\title{
MUERTE Y REPRESENTACIÓN EN EL CINE DE ALBERT SERRA
}

\author{
DEATH AND REPRESENTATION \\ IN THE CINEMA OF ALBERT SERRA
}

\section{Virginia TRUEBA MIRA}

Universitat de Barcelona trueba@ub.edu

Resumen: Con motivo de la película de Albert Serra, La muerte de Luis XIV (2016), este trabajo se propone pensar el afuera de la representación, entendido en el sentido de algunos pensadores postmetafísicos - Foucault, Deleuze, Blanchot - como aquello de lo que ningún orden de semejanza puede hacerse cargo por constituir una alteridad radical que, en grado límite, es la de la muerte misma. Ahora bien, la película de Serra se tensiona, ya no solo en la dirección de una muerte irrepresentable sino también de una muerte oculta tras unos órdenes de representación que, en este caso, son de dos tipos: el cortesano, y el que más interesa aquí, el médico-clínico, indicativo por lo demás de un tipo de ceguera que este cine insiste en subrayar.

Palabras clave: Albert Serra; pensamiento contemporáneo; cine español; representación

Abstract: On the occasion of the film by Albert Serra, The Death of Luis XIV (2016), this work intends to think the outside of representation, understood in the sense it has in some postmetaphysical thinkers - Foucault, Deleuze, Blanchot — as that of which no order of similarity can take charge because it constitutes a radical otherness. That otherness is, in a maximun degree, that of death. Now, Serra's film gets strained at the moment where death stops being seen because it gets hidden behind representational systems that, in this case, are of two types: the courtier, and the medico-clinical. It is this type of blindness that Serra's cinema puts on the stage.

Key words: Albert Serra; Contemporary thinking; Spanish cinema; representation 
En medio de antiguas tumbas, unas grandes, otras pequeñas, existe una senda para el ganado y las ovejas

Hay algo que llama poderosamente la atención en la película de Albert Serra, La muerte de Luis XIV (2016), desde su primera secuencia. Me refiero a la extraña combinación de materialidad e indefinición que presentan sus imágenes, algo que no es (solo) una cuestión de técnica cinematográfica. Trataré de explicarlo a continuación.

Con materialidad me refiero al escenario físico en que tienen lugar las acciones de la película, todo un mundo de continuidades donde no se sabe nunca dónde empiezan las cosas y dónde terminan, un mundo abigarrado de paños y telas (desde cortinas, sobrecamas, colchas... hasta blusones, camisas, todo lleno de volados de encaje,...), de pelucas imposibles, de cuerpos (tanto humanos como animales), de cuadros (muy en especial, retratos), de espejos (donde todo se abisma), de manjares exquisitos en soportes refinados, en fin, un conjunto de texturas que casi pueden tocarse. Es difícil en este aspecto marcar la diferencia, por ejemplo, entre las naturalezas muertas y las vivas en esta película, incluida la naturaleza del propio monarca, a quien vemos mayormente en su cama, primero con dolores contenidos, más tarde insoportables, luego ya postrado, tal vez muerto, para mostrársenos al fin cadáver, todo ello en una progresión en la que resulta imposible establecer puntos de inflexión determinantes. Pese a que la película está rodada casi toda ella en el interior de la estancia del monarca -Palacio de Versalles, 1715-, las (pocas) escenas de exteriores participan también de esta materialidad que se diría infinita, de acuerdo al mismo universo físico y matemático que la ciencia acaba de descubrir y que por ello mismo no podrá ya en lo sucesivo funcionar como norma, pues es, en propiedad, inabarcable.

Puede hablarse de la materialidad en esta película recurriendo al concepto de pliegue, en el sentido que le da Gilles Deleuze en su estudio sobre Leibniz y el Barroco titulado precisamente $E l$ pliegue (1988). Deleuze explica en este texto que el Barroco no inventa la «cosa» pliegue —que el pliegue ya existía con anterioridad: en Oriente, en Grecia, en Roma, en el Románico, en el Gótico-, pero sí le da un tratamiento específico en el momento en que curva y recurva los pliegues llevándolos hasta el infinito (Deleuze, 2015: 11). Más allá, no obstante, de lo plegado, lo que Deleuze estudia aquí es el elemento formal del pliegue, el cual solo pudo aparecer «en lo inconmensurable y la desmesura, cuando la curvatura variable ha destronado al círculo» (Deleuze, 2015: 54), es decir, en el momento del Barroco. En este aspecto, el mundo de tejidos (o texturas) que presenta La muerte de Luis XIV

\footnotetext{
${ }^{1}$ Le robo esta cita a Esther Ramón, quien la utilizó como epígrafe para abrir ese inmenso libro de poemas que es Reses (Gijón, Trea, 2008).
} 
puede definirse como un mundo de pliegues, que conduce a cierta «ubicuidad de lo viviente» (Deleuze, 2015: 19), es decir, a cierta inmanencia².

Llama la atención de la película el modo en que tiene lugar en este escenario la muerte del rey, integrada de tal modo en la materialidad que acabo de referir que apenas se percibe, lo que no deja de llamar la atención teniendo presente que quien muere es un rey y, además, no cualquier rey, es Luis XIV, el Rey Sol, Luis el Grande —en magnífica interpretación de Jean-Pierre Léaud-. La película trata en este sentido la muerte (del monarca) desde su más pura indefinición, de ahí que pueda decirse literalmente que, como espectadores, no vemos esa muerte, no asistimos a esa muerte, lo que no deja igualmente de sorprender dado el título mismo de la película.

Lo que me propongo en este trabajo es pensar precisamente esa indefinición. Para ello me apoyaré en el marco de cierto pensamiento francés contemporáneo que ha trabajado en el terreno de una lógica a la que podríamos denominar, en sentido laxo, borrosa, que desmontó la lógica de los viejos dualismos metafísicos e identitarios. En última instancia, aquel fue un pensamiento que intentó pensar, no lo que es posible pensar sino lo que no se deja pensar y también desde qué (no) lugar se da a ver eso que no se deja pensar. Desde esta perspectiva, es un pensamiento que puso sobre la mesa conceptos con los que las artes, la literatura y la propia filosofía han trabajado desde entonces, entre ellos, el concepto de diferencia (en el sentido que tiene en Jacques Derrida, como aquello que impide a toda representación contener la totalidad de lo representado), el de simulacro (en el uso que le da Gilles Deleuze cuando propone una inversión del platonismo que desplace la dialéctica original / copia) o, en especial, por lo que al tema propuesto aquí se refiere, el concepto del afuera tal como lo entiende Michel Foucault a partir de Maurice Blanchot, un afuera como aquello que más se resiste a ser pensado, a organizarse en este aspecto en un orden de semejanza, un afuera (que no un exterior) que supone una alteridad radical y que, en su expresión última, remite a la misma muerte.

Pues bien, entiendo que el cine de Serra permite ser interpelado desde esta lógica borrosa. Se trata de un cine que, además de ocuparse temáticamente de la muerte, resiste toda representación (por naturaleza, totalizadora o totalizante), por eso es un cine que no trabaja con momentos sobresalientes, los que constituyen el grueso de la narración más convencional. Lo que le interesa a este cine es, por el contrario, eso que sucede entre los momentos culminantes, eso que no destaca, que no varía, que permanece inalterable y que, al mismo tiempo, es la condición de posibilidad de todo relato. Podría decirse que no es un cine de puntos de inflexión sino de líneas continuas que discurren en trazado imperceptible —en el pensamiento de Foucault el afuera es una línea a la que él mismo denomina oceánica, la de la realidad en su extensión absoluta, sin pliegue alguno, representada, por ejemplo, por la figura de Moby Dick ${ }^{3}$ - . Así ocurre, por ejemplo, en Honor de cavalleria (2006), una muy especial

\footnotetext{
${ }^{2}$ La autora del presente trabajo ha estudiado recientemente el concepto de pliegue en la película de Serra desde esta perspectiva deleuziana (Trueba, 2018).

${ }^{3}$ Es la novela de Herman Melville la que Foucault y luego Deleuze ponen como ejemplo de la línea de la muerte, la línea ballenera, esa «cuerda al cuello», la llaman, con que se nace, y de la que habla explícitamente la novela, por ejemplo, en su capítulo LX, recordado asimismo por Foucault y Deleuze. El texto de la novela dice así: «Todos los hombres viven envueltos en estachas de ballena. Todos nacen con la cuerda al cuello, pero sólo al ser arrebatados en el rápido y súbito remolino de la muerte, es cuando los mortales se dan cuenta de los peligros de la vida, callados, sutiles y omnipresentes.
} 
versión (o per-versión, como la llamaría Leopoldo María Panero) de Don Quijote, en la que asistimos a lo que ocurre entre aventura y aventura de los personajes, el entre donde tiene lugar ese tiempo muerto, en el que no pasa nada salvo el mismo pasar, tiempo muerto que pocas veces el cine occidental ha interrogado. Sí lo hace la propuesta de Serra a la que podríamos aplicar las palabras de Foucault, referidas a las ficciones de Blanchot, que dicen así: «consiste[n] no en hacer ver lo invisible sino en hacer ver hasta qué punto es invisible la invisibilidad de lo visible» (Foucault, 1997: 13).

2. La novedad de esta película está en tratar la muerte, como acabo de decir, no como ese instante representativo en donde todos la re-conoceríamos sino como esa continuidad que ha estado desde siempre ahí, al modo de una presencia no-presente (que no ausente), que actuaría entonces como un soporte armónico (el bajo continuo de la música, precisamente barroca, imperceptible pero necesario, sin el cual la pieza no existiría). La muerte no es en esta película algo diferenciado de la vida sino aquello que la sustenta. En los períodos de mayor agonía del rey no podría decirse si es la vida que está apagándose o es la muerte que está avanzando. La muerte aquí es todo el rato coextensiva a la vida (Deleuze, 2017: 15). Esta no es una película de límites y por eso tampoco acaba con la muerte del monarca. No hay aquí, por tanto, dos realidades distintas sino una sola en la que todo sucede, la vida sucede ahí, en esa muerte que es lo lejano más cercano, es decir, un afuera que no es en propiedad un exterior, pues «se encuentra más allá de todo mundo exterior» y al mismo tiempo «más próximo que cualquier mundo interior» (Deleuze, 2014: 177).

Nada más empezar a ver la película se activa en el espectador algo que podríamos denominar una espera, con la particularidad de que se trata de una espera que no culminará en ningún momento, porque lo esperado no acabará de comparecer, no habrá comparecido ni siquiera cuando lleguen los títulos de créditos al final. Transcurrida apenas una hora de película (no estamos aún ni en su primera mitad) el rey manda llamar al Cardenal de Rohan, pues piensa que está a punto de morir. Poco después, sin embargo, debe reconocer, «mi hora no ha llegado aún». El Padre Tellier, de Palacio, lo corrobora: «la hora de la extremaunción aún no ha llegado». En esta película no hay lo esperado, hay la espera, que no es lo mismo, espera nunca cumplida, nunca resuelta. Hay el desastre, en el sentido que el concepto tiene en toda la obra de Maurice Blanchot, es decir, aquello que carece de referente, que nos hace perder pie, que impide toda protección, que nos sitúa a la intemperie. El desastre es aquí la ausencia de un último suspiro, de una última palabra, de aquel gesto (aterrado o resignado o esperanzador) de quien entiende que todo está a punto de acabar. El desastre es ese no (poder) ver la muerte del rey. Un desastre que configura, al mismo tiempo, la gran oportunidad.

Y es que la muerte, en realidad, ha estado siempre ahí: cuando vemos al rey en la primera escena en la silla de ruedas, cuando declara haber pasado una mala noche, cuando se queja del dolor de la pierna, cuando aparece la mancha negra en el pie... La muerte está ahí, en realidad, desde siempre y

Y si uno es un filósofo, aunque esté sentado en una lancha ballenera no sentirá un ápice más de terror que sentado ante el fuego del anochecer, con un atizador y no un arpón al lado» (Melville, 2010: 347). 
para siempre. Está desde el segundo primero de la película en que se escucha (sin ver aún) el sonido de los pájaros y el crujido de la madera de, tal vez, un carruaje antiguo. No es un carruaje, lo sabremos enseguida, es la silla de ruedas del rey desplazada por dos criados en los jardines de Palacio: un carruaje venido a menos, como la misma muerte.

Esa ambigüedad en relación a los límites entre vida y muerte es el punto de partida del cine de Serra, y esto es lo que hace que la imagen del cadáver resulte tan decisiva al situarnos de un modo extraño ante aquella presencia no-presente de la muerte. La relación con el cadáver es la relación directa con la muerte, pero con esa muerte que, como dije, no constituye un exterior a la vida sino un afuera. El cadáver está ahí, en toda su concreción, pero es la concreción de alguien que no está. ¿Qué vemos entonces cuando miramos un cadáver? Es la pregunta que la película se resiste a responder. La excepción aquí son los médicos, enseguida lo veremos: incapaces de enfrentarse a la ambigüedad inquietante de la muerte, a su carácter de pregunta sin respuesta, el cadáver les sigue hablando como si continuara vivo. La muerte se ha convertido para ellos (tengamos presente que la película nos sitúa en los comienzos de la clínica moderna) en unidad de medida de la propia vida.

En un orden de cosas distinto, y como antes comenté, no debe olvidarse quién muere en esta película. Se trata de Luis XIV, el representante paradigmático de las monarquías absolutas europeas. Es a ese monarca al que Serra concede una muerte, por decirlo así, cualquiera, insignificante, imperceptible, de tal modo que a la pregunta de cuándo muere el rey sigue la de quién muere en realidad en esta película. Serra trabaja aquí con los restos de aquella representación del monarca, de acuerdo a una idea que él mismo ha repetido al hablar de Hans-Jürgen Syberberg: que la fuerza del pasado es la de su opacidad, no la de su transparencia (Serra, 2017: 424). Es a lo largo de toda la película (ya la aparición de la silla de ruedas es significativa) pero, en especial, en su parte última cuando no estamos ya muy seguros de qué representa el personaje. Serra ha escogido para su construcción (de una imagen no representativa de Luis XIV) los últimos días de la vida del monarca, aquellos en que lo único que corona ya su cabeza es una peluca imposible, imagen de los pliegues infinitos de la época tras los cuales hay... más pliegues, en un movimiento que no termina nunca (no encuentra su fundamento último) y que por ello mismo acaba tocando aquella nada atronadora (y barroca) del conocido soneto de Luis de Góngora. Esa peluca sostiene al rey, mejor dicho, a ese cuerpo que ya no puede erguirse, tal vez el único soporte para un mundo que está dejando de existir (dos luises más y c'est fini, una nueva soberanía vendrá a sustituir a la vieja).

Por eso la de Serra es aquí también una deconstrucción del fundamento de la soberanía. El cadáver del rey, abierto al final en canal para disfrute (racionalista) de la nueva ciencia, podría ser en este aspecto correlato del cadáver (recuérdese que en 1662 se había creado en la Casa de fieras de Versailles) de aquel elefante a cuya autopsia asistió el propio Luis XIV en 1681 en una lección (ceremonia) de anatomía, escena que, desde el libro de H. F. Ellenberger, Médicines de l'âme. Essais d'historie de la folie et des guérisons psychiques (1995) recuerda Derrida en la undécima sesión de su seminario de 2002 sobre La bestia y el soberano al hilo de una reflexión sobre el orden del saber en su relación con el orden del poder. El monarca «conserva, tiene en su posesión a la inmensa bestia, tiene 
el inmenso cadáver a su disposición, como un objeto para su poder, para su saber, para su tener y para su ver, y para lo que le venga en gana», escribe Derrida (2010: 332). ¿No es ahora el monarca, en la película de Serra, para los médicos ese mismo, también, inmenso cadáver?

Asistimos, pues, en esta película a una muerte cualquiera pero también a la muerte de un hombre cualquiera. No es la muerte personal de la que trata esta película sino de la muerte impersonal, de la muerte que es de todos y de nadie. No es la muerte del «yo muero» sino la muerte del «se muere», en la diferenciación que establece Foucault desde Blanchot (Deleuze, 2017: 20). Y es que, aunque para la ciencia moderna la muerte natural ha dejado de existir para ser sustituida por la muerte a causa de, uno no se muere solo de enfermedad o accidente o..., sino que se muere de la misma muerte, «por eso Rilke - ha explicado Blanchot- se negó tan brutalmente a saber de qué moría, no queriendo poner entre él y su fin la mediación de un saber general» (Blanchot, 2012: 116).

La muerte que vemos (sin ver) en esta película es la muerte del «morir», esa que no acaba de llegar nunca (de ahí la espera), de la que nadie tiene experiencia pues la propia muerte nos lo impide (de ahí la imposibilidad de su representación, no es representable ese morir). Esa muerte del morir es la que debe respetarse, pues es lo que verdaderamente nos supera. Hay que «ser fieles a lo que nos excluye» escribe Blanchot (2012: 118), lo que quiere decir aprender a convivir con esa muerte (lejos de la idea de su superación o sobrevivencia). Cuando hayamos aprendido a convivir con esa muerte, solo entonces sabremos morir. Y es que para Blanchot el problema es que «nos hemos olvidado de morir» (2012: 137). Esta es una reflexión importante que adquiere su pleno sentido si atendemos a la experiencia de los campos de la muerte del nazismo, en los que paradójicamente no se moría sino que se fabricaba muerte, esos campos que culminan, como tantas veces se ha denunciado desde cierto pensamiento contemporáneo, una parte del proyecto moderno. La película de Serra pone sobre la mesa (sobre la pantalla) tanto ese olvido (en especial en relación a los médicos), como esa convivencia, donde se sitúa la apuesta fílmica de la película y también la particular gestualidad del propio monarca. ¿A qué me refiero con la gestualidad?

La película se desarrolla todo el rato entre aquellos pliegues infinitos donde se pierde la mirada a los que ya me referí. No obstante, en relación a los personajes (los médicos en especial) les vemos al margen de esos pliegues, entre pasivos e incluso hieráticos en sus movimientos, como si permanecieran en una línea distinta a la de la materialidad que habitan, una línea recta en este caso, que no abandonarán en ningún momento. Ahora me referiré a ello. Hay, sin embargo, una excepción significativa en relación a esta actitud: la del propio rey.

Luis XIV está todo el rato en un lugar distinto al de los médicos, ya no solo por ser el soberano, también por ser el enfermo y el que va a morir pero también, y sobre todo, por su capacidad de plegarse al mundo de pliegues donde también habita. En este aspecto, y paradójicamente, solo el rey es en esta película un personaje vivo, los demás, muy en especial los médicos, son más bien espectros mecanizados en busca de lo imposible: esas verdades últimas de la ciencia que no acaban de llegar nunca. 
Los modos de plegar-se el rey a su entorno son varios y distintos: destaca la escena inicial con los perros (un contacto con el animal que los médicos han desaconsejado sin embargo), también su rostro ilusionado al escuchar los tambores y oboes de la fiesta de Saint Louis filtrados en la habitación desde el exterior (mirada la del rey entonces respondida con condescendencia por la de su criado, indiferente, como el resto de personajes, al acontecimiento festivo), y está, sobre todo, esa secuencia de casi tres minutos, en la que el rey, después de una ligera mejoría, dirige su mirada (recogida en un intenso primer plano) a un punto de fuga, fuera de cámara, que parece interpelarnos como espectadores. El rey mira ese lugar no identificado, tal vez no identificable, mientras escucha en su imaginación la música que la historia no ha inventado aún, el kyrie de la Misa en do menor de Mozart. Es la primera y última vez que le vemos mirar fijamente. Él, que es objeto de todas las miradas, no ha osado mirar a nadie en toda la película (al pájaro de la jaula en una sola ocasión). La mirada de esta escena apunta a un fuera de cámara pero un fuera que tiene mucho de dentro en tanto se produce en la interioridad del monarca, en la interioridad de la estancia, y nos incluye también a nosotros como espectadores, absorbidos o tragados por la secuencia, pues resulta imposible permanecer al margen.

Aquí me gustaría arriesgar una interpretación: ese fuera tal vez pudiera leerse como correlato de la línea de la muerte de la que estoy hablando aquí, manifestada siempre desde un lugar incierto, y que solo en momentos especiales se deja percibir. Si aceptamos que la mirada del rey en esta secuencia se dirige a la línea de la muerte, entonces esa mirada constituiría un modo de «cabalgar»o «plegar» esa línea. Esta es la acción necesaria de la que habla Deleuze, ya que es cierto que uno puede vivir al margen de esa línea como hacen los médicos, o vivir atraído fatalmente por ella ${ }^{4}$, pero uno también puede (y debería) con-vivir con ella, y con-vivir quiere decir aquí «plegar el mundo para poder vivirlo, para que no se dé de una sola vez» (Deleuze, 2014: 180), hacerle un interior a ese afuera - el ojo del huracán del que habló también Henri Michaux recordado por Deleuze ${ }^{5}$. La mirada del rey aquí podría ser entonces el particular pliegue que este realiza en ese morir en el que, en breve, ocurrirá su propia muerte ${ }^{6}$.

Quisiera arriesgar un poco más la interpretación. He dicho que el rey cabalga o pliega esa línea, con-vive con ella (la esquizofreniza, diría el psicoanálisis). Me pregunto entonces, ¿no es el cine precisamente el arte que nos permite convivir, más que ningún otro, con la muerte en tanto arte de espectros? Así lo dice, con la simplicidad característica, aquel niño que se acercó en cierta ocasión a Max Jacob, en anécdota recordada por Alberto Ruiz Samaniego: «el cine se hace con los muertos. Se les coge, se les hace caminar y eso es el cine» (2013: 23). En este aspecto, la mirada del rey podría

\footnotetext{
${ }^{4}$ El suicidio sería entonces la tentativa vana de abolir el misterio de la muerte, el secreto de su llegada imprevista, uno quiere matarse para que el futuro deje de ser «la oscura reserva de la muerte indescifrable», en palabras de Blanchot recordadas por Deleuze (2017: 16).

${ }^{5}$ En la misma dirección de Deleuze, otro pensador como Jean-Luc Nancy escribe en su texto El intruso las siguientes palabras: «Aislar la muerte de la vida, no dejarlas entrelazarse íntimamente, cada una intrusa en el corazón de la otra: he aquí lo que nunca hay que hacer» (Nancy, 2007: 24). En el capítulo LXXIV de Moby Dick, el narrador escribe estas palabras con las que podría definirse el ejercicio del pliegue, que es de lo que aquí se trata también: «ipor qué tratáis de 'ensanchar' vuestra mente? ¡Sutilizadla!» (Melville, 2010: 401).

${ }^{6}$ Explica Deleuze que «el 'yo muero' sería el instante en que, en tanto que persona, coincido con la línea del 'se muere', ocupo mi lugar en el 'se'» (Deleuze, 2017: 20).
} 
remitir también a la mirada del cine, a ese pliegue que es también el del cine en su relación a la muerte, mirada que, a su vez, nos invita a plegar-nos con ella y... morir ahí, en la pantalla. Arte espectral por excelencia, el cine «nos explica aquello de lo que no se vuelve, nos explica la muerte», en palabras de Derrida (2013: 339).

Nada que ver esa mirada del rey con la mirada frontal e invasora de Fagón, el médico particular del rey, que ocupa toda la pantalla en la última secuencia de la película para desde ella anunciarnos el futuro con su frase lapidaria, «la próxima vez lo haremos mejor». La cosa marcha. La modernidad avanza.

3. La cosa va bien porque los médicos permanecen todo el rato al margen de la línea del afuera. Han construido, no un interior en el huracán, sino una autopista al futuro que les permite saltarse $-\mathrm{y}$ perderse $^{7}$ - los caminos (pliegues también) de la experiencia (del morir). Lo que ganan en claridad lo pierden en devenires. Los médicos sí son en este aspecto el exterior de la propuesta fílmica de Serra, ese exterior que Serra pliega aquí, no obstante, desde toda su ironía.

Obsesionados por encontrar respuestas («lo que me gustaría —dice literalmente uno ellos al finalizar la primera media hora de película- es tener respuestas»), no abandonarán la lucha en ningún momento, ni siquiera finalizada la película. «Señores, el rey ha muerto», afirma Fagón tras la auscultación del cuerpo, e inmediatamente después el secretario se apresura a confirmar con el libro en la mano: «Dejo constancia, Sr. Fagón». La muerte es aquí ese certificado de defunción anunciado por los médicos-notarios. A partir de entonces será esa misma muerte (antes ha sido la enfermedad) la que les proporcione las respuestas ciertas (a las preguntas que ellos mismos han formulado). El cadáver está vivo para los médicos, es el que les permitirá construir a partir de entonces una biblioteca futura, un orden de la memoria (un saber que deberá ser después asimilado y defendido). La autopsia (la autopista) continuará, afirman. El cerebro, advierte Fagón, se deja para más adelante.

¿Cuándo entonces la muerte?, ¿cuando la ciencia haya despedazado el cadáver entero y solo queden unos restos abandonados a una suerte incierta? Nos hemos olvidado de morir. Serra insiste con toda su ironía en esta locura que define lo vivo en relación a la muerte, en el sentido asimismo de Foucault en El nacimiento de la clínica, como si solo una negatividad profunda hubiera podido constituir al hombre moderno como objeto de la ciencia. Incapaces de ver más allá de lo pensado, la visibilidad de los médicos aquí es solo la de lo controlable, lo catalogable, lo mensurable... como ejemplifica a la perfección ese conjunto de ojos de cerámica, perfectamente numerados, que vemos en las primeras secuencias de la película y desde los cuales los médicos leerán los ojos del rey en lo

\footnotetext{
${ }^{7}$ De una pérdida, tras una supuesta superación, habla también Clarice Lispector en La pasión según G. H. en relación a la imagen del desierto. Lo dice así: «Hasta el momento en que vi la cucaracha, siempre había dado un nombre a lo que estaba viviendo, para poder salvarme. Para escapar de lo neutro, había abandonado hace mucho tiempo el ser por la persona, por la máscara humana. Al humanizarme, me había librado del desierto. Me había librado del desierto, sí, ipero también lo había perdido!» (Lispector, 2001: 80).
} 
sucesivo. La película refleja lo que la ciencia médica de la época, de la mano de la matemática y de la física, practicará a partir de entonces: una visión del mundo solo posible a través del instrumento ${ }^{8}$.

Imposible desde ahí enfrentar la línea (no pensable) del morir. Apenas hay variaciones en el lugar que ocupan los médicos, que ni siquiera necesitan convencerse de que es el adecuado. Su línea recta discurre impasible, superpuesta a la infinidad de pliegues que la envuelven. Pase lo que pase, aunque pase la muerte, la línea no se altera. Será Fagón el encargado de dar el toque definitivo a la película con una última frase dirigida al espectador, la que antes recordé: «la próxima vez lo haremos mejor». El error se ha producido, pues, en el campo del saber, en la insuficiencia de sus conocimientos, no en la óptica desde la cual se ha mirado. A partir de aquí, el futuro solo puede ser ventajoso gracias al progreso (inherente) de la nueva ciencia. «La destreza (no el azar) sustituye a la vieja sabiduría y a la vieja prudencia», ha reconocido Deleuze en su estudio sobre el siglo barroco y el cartesianismo que lo atraviesa (2015: 91). Esa destreza es la de los médicos aquí, confiados en sus propias posibilidades de conocimiento, una vez, eso sí, se han desprendido de las preguntas incómodas, entre ellas, la del ser de la enfermedad - la del ser del universo en el terreno de la física y la matemática一, esta última convertida ahora en algo que debe ser vencido gracias a la eficacia del método y el instrumento.

En este sentido, Luis XIV es en la película de Serra, entre otras cosas, un caso a estudiar, un mecanismo que no ha funcionado como debiera. De las conversaciones que tienen los médicos se deduce que la única diferencia entre un cuerpo vivo y uno muerto es el funcionamiento de su mecánica. En este aspecto, la línea recta en la que se sitúan los médicos encontraría su correlato objetivo en el sonido del tic-tac del reloj que se oye todo el rato en la película (sobre el cual se percibe también, sin embargo, el sonido modulado de los pájaros). Estamos ante la representación del tiempo repetible, no cualitativo, de las ciencias humanas matematizadas, como escribe Walter Benjamin en su conocido texto sobre el drama barroco alemán recordando una reflexión de Bergson (Benjamin, 1990: 84). Ese reloj es el que pone voz a la visibilidad que sostiene la línea recta que los médicos habitan.

No es para olvidar el momento final de la autopsia del rey, cuando los médicos extraen (en gesto inverso al de cuando intentan, entre lo absurdo y lo cómico, que ingiera, ya moribundo, exóticos y variados alimentos de acuerdo a un programa de salud que habla, entre otras cosas, de una concepción de la vida como puro consumo o puro gasto) el intestino del monarca, convertido por Serra ahora en lo que parece realmente una larguísima butifarra negra. El menú está preparado, pero no para disfrute del cuerpo sino para el de un determinado pensar en el que se cifrará a partir de entonces la clave de la existencia. La muerte es a partir de la modernidad, como estudió Foucault en El nacimiento de la clínica, la perspectiva absoluta de la vida, la que proporciona, en el horizonte de la utopía científica, la máxima luminosidad a la oscuridad de la vida ${ }^{9}$.

\footnotetext{
${ }^{8} \mathrm{El}$ asunto es, entre otras cosas, que entonces el mundo tendrá que hacer todo lo posible por parecerse a esa representación construida sobre una serie de parámetros mensurables. Hay una escena en la película que merece recordarse en este sentido. El médico del rey, de nuevo Fagón, se permite sugerir al monarca hacia mitad de la película, con la prudencia, eso sí, del que se sabe servidor, que tal vez son las lumbares y no la pierna, lo que le duele. Algo no le cuadra a Fagón. No le cuadra la realidad. El rey ni siquiera contesta, un ligero gesto de desprecio resulta suficiente para zanjar la cuestión.

9 De esta visión foucaultiana parte Alberto Ruiz Samaniego en un interesante texto dedicado a las imágenes cinematográficas de las pasiones tristes, en el que se detiene en el cine de Stan Brakhage en The act of seeing with one's
} 
4. La muerte de Luis XIV despliega, por tanto, una materialidad infinita sobre una línea que no vemos porque es una línea sin forma, sin posibilidad de representación. Esa línea es un afuera que sostiene todo el interior de la película. Es la línea de la muerte, del «se muere», esa línea que no podemos nunca experimentar pues cuando «yo muero» ya no hay nadie que esté ahí para re-conocerla. Somos los «infinitamente muertos», escribía Rilke al final de las Elegías en cita que ha recordado Blanchot (2004: 131).

Mi propuesta aquí ha sido leer esa línea en la película de Serra desde aquel pensamiento francés de los sesenta y setenta empeñado en pensar lo que no se deja pensar pero que, precisamente por ello, tal vez sea, a lo Samuel Beckett, lo más interesante pensar. No se trata de que antes de la aparición de ese pensamiento la filosofía ignorara que había lo no pensado (lo no pensable). Esto lo ha explicado muy bien Deleuze. Se trata de que, en este aspecto, la filosofía clásica asociaba lo no pensado (lo no pensable) a aquello que tenía una naturaleza distinta del pensamiento. La particularidad de cierta filosofía contemporánea es que concibe lo no pensado como connatural al pensamiento, o sea, que el pensamiento estaría en una relación fundamental con lo no pensado (Deleuze: 2017: 33). Es en este último escenario donde resulta especialmente operativo el concepto de pliegue, que rompe el dualismo de la filosofía clásica para problematizar el juego de la representación basado siempre en la contraposición del original y la copia, es decir, de la verdad entendida como adecuación a algún tipo de orden superior. En este aspecto, el cine de Serra tiene más que ver con cierto cine oriental (el de Hong Sang-soo por ejemplo, al que el mismo Serra se ha referido en alguna ocasión) que con el cine occidental (al menos el más comercial), un cine oriental que converge con la deconstrucción de la identidad operada dentro del pensamiento postmetafísico del que participan autores como Foucault, Deleuze o Blanchot.

Quiero destacar, ya para acabar y a modo de conclusión, que si bien es cierto que esa línea del afuera es irrepresentable, y que el mérito de La muerte de Luis XIV es mantenerse precisamente en esa no-representación, también lo es que solo cierta experiencia estética - y la del cine es aquí experiencia privilegiada - puede hacerse cargo de esa línea, es decir, presentárnosla, proporcionarnos cierto trato con eso que es intratable, con eso a lo que nuestras sociedades actuales, muy en especial, han dado la espalda. La muerte es ya algo producido, algo debido a (fumar, no hacer ejercicio, no comer bien...) y es, además, y últimamente, responsabilidad de uno mismo (por no haberse cuidado). De modo complementario, la muerte es lo que se oculta (en tanatorios de arquitectura idéntica a la de los museos de arte contemporáneo o a la de los hoteles de 4 o 5 estrellas, a veces de menos), la muerte es la que la medicina busca demorar y demorar, por eso nos mata para vivir, o para morir sanos. Solo en situaciones excepcionales puede percibirse que los límites de la muerte y de la vida no están, en

own eye (El ojo de ver con el propio ojo de uno mismo, 1967) como paradigma de este, lo llama así, «archifenómeno escópico» (2015: 114). Su reflexión, un poco más adelante, sobre Persona de Ingmar Bergman, apunta al hecho de que cuanto más se esfuerza el discurso médico por «enunciar y cauterizar los signos del dolor, tanto más profundo y mudo se vuelve su misterio», tanto más angustiosa se vuelve la presencia del sufrimiento, y ello porque hay «un fondo humano que permanece sin ser pensado, una esencia del dolor que se sustrae a toda voluntad de poder y de saber» (Ruiz Samaniego, 2015: 124). 
realidad, nada claros, y que la muerte no es exactamente lo que pone fin a la vida. Solo cierto tipo de experiencia estética como digo (cierto tipo de ficción), puede hacerse cargo de esa muerte, no para salvarnos ni protegernos, no se trata de ello, sino para poder sostenerle la mirada — como Luis XIVen su condición de invisibilidad absoluta.

\section{Referencias bibliográficas}

BENJAMIN, W. (1963): El origen del drama barroco alemán. Madrid, Taurus, 1990.

Blanchot, M. (1955): El espacio literario. Barcelona, Paidós, 2012.

DeLeUZE, G. (1986): La subjetivación. Curso sobre Foucault. Buenos Aires, Cactus, 2017. (1988): El pliegue. Barcelona, Paidós, 2015. (2014): Conversaciones. Valencia, Pre-Textos.

DERRIDA, J. (2001-2002): Seminario. La bestia y el soberano. Buenos Aires, Manantial, 2010. (2013): Artes de lo visible. Pontevedra, Ellago.

Foucault, M. (1966): El pensamiento del afuera. Valencia, Pre-Textos, 1997.

LISPECTOR, C. (1964): La pasión según G. H. Barcelona. Muchnik, 1988.

MelviLLE, H. (1851): Moby Dick. Barcelona, Planeta, 2010.

NANCY, J.-L. (2007): El intruso. Buenos Aires, Amorrortu editores, 2007.

RUIZ SAMANIEGO, A. (2013): Ser y no ser. Figuras en el dominio de lo espectral. Murcia, Micromegas. (2015): Las horas bellas. Madrid, Abada.

SERRA, A. (2018): Diario de Kassel (versión kindle).

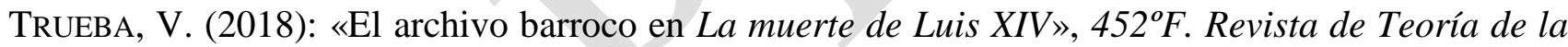
Literatura y Literatura Comparada, 19, pp. 40-56. 